\title{
Digestion of grass lipids and pigments in the sheep rumen
}

\author{
By R. M. C. DAWSON AND NORMA HEMINGTON \\ Biochemistry Department, ARC Institute of Animal Physiology, \\ Babraham, Cambridge
}

(Received I November 1973 - Accepted 5 February 1974)

\begin{abstract}
I. Digestion of grass lipids and pigments in the rumen of the sheep has been studied during starvation and following the administration of ${ }^{14} \mathrm{C}$-labelled grass.

2. Both galactolipids contained in chloroplasts are rapidly degraded, although monogalactosyldiglycerides disappear faster than digalactosyldiglycerides. It was concluded that rumen micro-organisms are mainly responsible for this degradation, although grass itself also contains enzymes which can degrade galactolipids.

3. Rumen contents can degrade added ${ }^{14} \mathrm{C}$-labelled mono- and digalactosyldiglycerides in vitro at a rate sufficient to account for the disappearance of galactolipids in the intact rumen. The initial enzyme attack is probably a successive deacylation to give monogalactosylglycerol and digalactosylglycerol.

4. Most of the chlorophyll pigments are rapidly converted into phaeophytins by loss of magnesium. A small proportion of chlorophyll $a$ and more of chlorophyll $b$ remains intact even after $24 \mathrm{~h}$ starvation. On the other hand, about half the phaeophytin undergoes further rapid decomposition to yield phylloerythrin.

5. Although the grass phospholipids are extensively degraded, $\beta$-carotenes and many nonpolar compounds, e.g. steroids, appear to undergo little change in the rumen.
\end{abstract}

It has been established that, when triglycerides are introduced into the rumen, they are rapidly hydrolysed with the liberation of free fatty acids, the glycerol also formed being fermented (Garton, Hobson \& Lough, 1958; Garton, 1964). By comparison, the fate of the complex lipids present in plant-leaf material has received little attention. 'These plant-leaf lipids are found for the most part in membrane structures such as those in chloroplast lamellae, mitochondria, endoplasmic reticulum and plasma membranes, although waxes are present as constituents of the leaf cuticle. Since these membranes account for most of the dry weight of the cell mass, and they contain $20-30 \%$ by weight of lipids, the latter are clearly major constituents of plant cells. In terms of mass, the main lipids of photosynthetic plants are those present in chloroplasts, i.e. monogalactosyldiglycerides, digalactosyldiglycerides and chlorophyll pigments; phospholipids (predominantly lecithin) are largely contained in the other membraneous structures (Kates, I970). It can be calculated from the results of Roughan \& Batt $(1969)$ that, in a ruminant consuming perennial ryegrass (Lolium perenne L.), each $\mathrm{g}$ of fresh leaf tissue contains about $4 \mathrm{mg}$ each of the two galactolipids and about $2.5 \mathrm{mg}$ of phospholipid. This suggests a daily intake of about $40-50 \mathrm{~g}$ of these complex lipids in a sheep and $300-400 \mathrm{~g}$ in a cow consuming grass pasture. In such animals by far the major fatty acid found in the rumen is stearic acid, with little linoleic or linolenic acid, and since the fatty acids present in the complex lipids of grass are these latter two fatty acids (Garton, I960; Czerkawski, I967) it follows that hydrolysis and hydrogenation must have occurred. It is known that the unsaturated fatty acids must be non-esterified for hydrogenation to take place in the rumen 
(Garton, Lough \& Vioque, 196ı; Hawke \& Silcock, I969; Kepler, Tucker \& 'Tove, 1971). Garton (1964) reported that mixed rumen micro-organisms could hydrolyse galactolipids, and 1)awson (1959) found that lecithin was broken down primarily by enzymatic deacylation, forming glycerolphosphorylcholine. Because of the important effect of dictary lipids on the fatty acid composition of ruminant tissue lipids (Cook, Scott, Faichney \& Iloyd-Davies, 1972), the metabolism of grass lipids in the rumen has been investigated further.

\section{EXPERI MENTAL}

The sheep were Clun Forest wethers with fistulated rumens. They were fed either on pasture grass to appetite or were given $1200 \mathrm{~g}$ hay-oats (5:1) once daily.

\section{Isolation of total lipid fraction}

A number of methods were examined for extracting lipids from rumen contents and from grass. The following procedure was the most effective for extracting total lipids and phospholipids. Rumen contents (usually $25 \mathrm{ml}$ ) were sampled through a fistula and treated with 6 vol. cthanol and warmed to $80^{\circ}$ for 15 min. To the mixture was added 12 vol. chloroform and, after stirring for $30 \mathrm{~min}$ at $50^{\circ}$, it was centrifuged $(2000 \mathrm{~g})$ and the residue re-extracted for a further $30 \mathrm{~min}$ at $50^{\circ}$ with 10 vol. chloroform-methanol $(2: \mathrm{I}, \mathrm{v} / \mathrm{v})$. The combined extracts were shaken with $0 \cdot 2 \mathrm{vol} . \mathrm{NaCl}$ solution $(9 \mathrm{~g} / \mathrm{l})$ and the lower phase was collected and taken to dryness in a rotary evaporator after which the lipids for analysis were re-extracted into $10 \mathrm{ml}$ chloroform. Repetition of the ethanol and chloroform-methanol extraction procedure resulted in about $5 \%$ more lipid being extracted, but its composition was the same as that of the original extract, so this step was not usually carried out. Grass was chopped into small pieces and the lipid extracted by the same method, using $6 \mathrm{ml}$ ethanol/g.

\section{Separation and examination of lipids}

Lipid fractionation was designed to obtain a general picture of the main lipolytic events occurring in the rumen. Preliminary fractionation of the lipids on a silicic acid column assisted the eventual examination of the lipids by thin-layer chromatography since the intensely coloured plant pigments were largely removed in the initial chloroform fraction. These pigments cause difficulties during plant-lipid fractionations (Allen, Good, Davis, Chisum \& Fowler, 1966). The elution of galactolipids with acetone is based on a method described by Vorbeck \& Marinetti (1965), who used solvents containing acetone to separate glycosyldiglycerides from phospholipids in extracts of bacteria. However, in the present fractionations many other polar lipids including, rather surprisingly, acidic phospholipids were also eluted by the acetone.

The lipids were subjected to an initial fractionation on a silicic acid column (Mallinckrodt). The slurry in chloroform was poured into a $200 \mathrm{~mm} \times 18 \mathrm{~mm}$ column and the lipid fractions were eluted successively with the following solvents: ( $\mathrm{I}$ ) chloroform, $300 \mathrm{ml}$; (2) acetone, $200 \mathrm{ml}$; (3) chloroform-methanol (9: I, v/v), $200 \mathrm{ml}$; (4) chloroform-methanol $(3: 2, \mathrm{v} / \mathrm{v}), 200 \mathrm{ml} ;(5)$ methanol, $200 \mathrm{ml}$. Details of the classes of lipid eluted are given in 'Table $\mathbf{I}$, which also indicates the solvents used for their subsequent 
'Table 1. Separation by column and thin-layer chromatography of the lipids in grass and the rumen contents of sheep

Eluting solvent

1. Chloroform

2. Acetone

3. Chloroform-methanol $(9: 1, v / v)$

4. Chloroform-methanol $(3: 2, v / v)$

5. Methanol
Main type of lipid eluted from the column

Hydrocarbons, plant pigments, fatty acids, neutral triglycerides, sterols and their glycosides

Galactolipids, ceramides, Chloroform-methanol-35 Mphosphatidylethanol* cardio- ammonium hydroxide lipin, pigment decomposi- $\quad(70: 20: 2$, by vol.) tion products Phosphatidylglycerol
phylloerythrin

Phosphatidylethanolamine

Lecithin .
Solvents used for thinlayer chromatography

Light petroleum-diethyl ether, $(19: 1, v / v)$ and $(4: I, v / v)$

Chloroform-methanol-1 3 Mammonium hydroxide (130:60:9, by vol.)

- Only found when grass samples were extracted initially with ethanol, and is likely therefore to be an artefact produced by the transferase activity of phospholipase I) (Dawson, 1967b). For details of column and thin-layer chromatography plates see pp. 328, 329.

examination by thin-layer chromatography on silica gel (Kieselgel 60 F254, E.Merck AG, Darmstadt, Germany). Major components were identified by the use of markers and, in certain instances, confirmed by isolation of the substances from thin-layer chromatograms, followed by determination of the visible spectra of pigments, or by studying the deacylation products of galactolipids and phospholipids (Dawson, 1967a).

\section{Pigments}

Considerable decomposition of many plant pigments occurred on the silicic acid column. Therefore, these were usually examined directly in the original lipid extract by paper or thin-layer chromatography. Carotene, xanthophylls, chlorophylls and phaeophytins were separated by ascending chromatography on Whatman No. I paper for $2-3 \mathrm{~h}$ in acetone-light petroleum (b.p. $\left.60-80^{\circ}\right)\left(\mathrm{r}_{3}: 87, \mathrm{v} / \mathrm{v}\right)$ at room temperature in the dark. These pigments were usually examined by direct chromatography of the lipid extracts prepared as described, but in some instances they were extracted by the procedure of Jeffrey (I96I). However, in the latter method, the more polar decomposition products of the pigments were partially lost into the aqueous phase on washing. These polar pigments remained at the origin on paper chromatograms, but could be separated by thin-layer chromatography on silica gel H (E. Merck AG) using, as solvent, chloroform-methanol-35 $\mathrm{M}-\mathrm{NH}_{4} \mathrm{OH}$ (70: $15: 1$, by vol.). Chlorophylls, phaeophytins and carotenoids moved near the solvent front, but they could be separated in a second dimension when light petroleum-diethyl ether-acetone $(35: 40: 20$, by vol.) was used as developing solvent.

The phase test for detecting loss of phytol residues from chlorophylls (Smith \& Benitez, 1955) was done by shaking a solution of the pigments in diethyl ether with an equal volume of $5.6 \mathrm{M}-\mathrm{HCl}$. Loss of pigment to the aqueous solution represented 
chlorophyllide or phacophorbide formation. In addition, the pigment in light petroleum solution was shaken with an equal volume of acetone-water $(3: 2, v / v)$, when passage of pigment into the aqueous phase represented a loss of phytol residues.

\section{${ }^{14}$ C-labelled grass}

In some experiments (c.g. Fig. I) grass labelled with ${ }^{14} \mathrm{C}$ was used. Pcrennial rycgrass $\mathrm{S}_{24}$ was cultivated in a growth chamber similar to that described by Grossbard $\&$ Barton ( 1963 ), in which the ${ }^{14} \mathrm{CO}_{2}$ in the environment was automatically maintained by the use of a $\mathrm{CO}_{2}$ monitor coupled with a generator. Activities of up to $350 \mu \mathrm{Ci} / \mathrm{g}$ wet grass were obtained. Details of this apparatus and its operation will be described in a later publication.

\section{Grass homogenates}

Perennial ryegrass ( 10 g) was cut into small pieces and homogenized in an CltraTurrax homogenizer in $50 \mathrm{ml}$ of freshly-prepared aqueous solution of salts ('rumen saline') resembling the composition of rumen liquor (Warner, 1956).

\section{Radioactive lipid substrates and their incubation with rumen contents}

Lipid substrates were prepared from ${ }^{14} \mathrm{C}$-labelled grass by lipid extraction followed by isolation of the lipids by column chromatography, and preparative thin-layer chromatography by methods described above. "The galactolipids were taken to dryness in the incubation tube and incubated at $37^{\circ}$ under $\mathrm{N}_{2}$ with I $\mathrm{ml}$ of strained rumen contents to which had been added $0.05 \mathrm{ml} \mathrm{I} \mathrm{M-glycerol} \mathrm{and} 0.05 \mathrm{ml}$ I M-galactose (to suppress any loss of ${ }^{14} \mathrm{CO}_{2}$ through oxidation reactions). The reaction was stopped by the addition of $\mathrm{I} 0 \mathrm{ml}$ chloroform-methanol $(2: \mathrm{I}, \mathrm{v} / \mathrm{v})$. The mixture was shaken with I $\mathrm{ml}$ of water, centrifuged, and the radioactivity in the upper aqueous phase was measured by scintillation counting. A sample of the upper phase $(0.5 \mathrm{ml})$ was mixed with $10 \mathrm{ml}$ Bray's solution (Bray, I 960) and counted using a Unilux II counter (Nuclear Chicago).

\section{Galactolipids}

Samples of mono- and digalactolipids to act as chromatographic markers were kindly provided by Dr T. Galliard. Galactolipids in larger amounts were prepared from grass samples as indicated and from these both $\beta$-D-galactopyranosyl-I, I'-D-glycerol and $\alpha$-D-galactopyranosyl-I,6- $\beta$-D-galactopyranosyl-I, $\mathrm{I}^{\prime}-\mathrm{D}$-glycerol were prepared by alkaline deacylation (Dawson, 1967a). Enzymatic decomposition products of $\left[{ }^{14} \mathrm{C}\right]-$ galactolipids were examined by shaking the incubation medium with 10 vol. chloroform-methanol $(2: \mathrm{r}, \mathrm{v} / \mathrm{v})$ and then, after adding $\mathrm{I}$ vol. of water, centrifuging to separate the upper aqueous methanol phase from the lower chloroform-rich phase. The latter was examined for lipid degradation products (free fatty acids and diglycerides) by thin-layer chromatography on silica gel $\mathrm{H}$ using either chloroformmethanol-water-acetic acid (85:15:10:4, by vol.) or light petroleum-diethyl ctheracetic acid (90:53:7, by vol.). The water-soluble products formed from monogalactosyldiglycerides were examined by paper chromatography in phenol saturated with water-acetic acid-cthanol (100: 10: I 2, by vol.) and from digalactosyldiglycerides in a 
solvent composed of ethyl acetate-pyridine-water (12:5:4, by vol.). Detection of aqueous decomposition products was by radioautography for I week, followed by treating the chromatogram with alkaline silver nitrate to reveal the cis-glycol grouping (Trevelyan, Procter \& Harrison, I950).

\section{RESULTS}

\section{General observations on the effects of starvation on rumen lipids}

Food, but not water, was withheld from a sheep which had previously been feeding normally on pasture grass. Lipid fractionations were performed on rumen contents removed I, 5 and $24 \mathrm{~h}$ after the termination of feeding. It was evident that chloroplast galactolipids were rapidly metabolized since, in samples removed $\mathrm{i} h$ after the end of feeding, they could hardly be detected in the rumen, although they were major components of the grass. In addition, the chlorophyll pigments present in the grass had undergone a considerable change since, $\mathrm{I} h$ after the end of feeding, the major peak in the absorption spectrum at $432 \mathrm{~nm}$ had shifted to one at $4 \mathrm{I} 4 \mathrm{~nm}$, indicating a loss of magnesium. Subsequently, the spectrum did not change, although the extinction intensity of the pigment / unit volume of rumen contents fell after $24 \mathrm{~h}$ starvation to $64 \%$ of that originally present, presumably as the rumen contents passed to the abomasum.

Similar experiments were performed on a sheep which had been previously fed on a diet of hay and oats. In contrast to the pasture diet, the oats provided considerable amounts of triglyceride and, in addition, galactolipids were virtually absent from the hay, presumably having been lost during drying and storage. During starvation there was rapid loss of the triglyceride accompanied by the appearance of free fatty acids, which consisted mainly of stearic and palmitic acids, the former presumably produced by biohydrogenation in the rumen.

On both diets there was no evidence of metabolism of other non-polar lipids (e.g. carotenoids, plant sterols) in the rumen, since their concentration remained constant during ruminal digestion. There was a steady fall in the concentration of phospholipids in the rumen during the experimental period. The predominant phospholipids of grass were phosphatidylcholine and phosphatidylethanolamine, and thelevel of each declined. However, the true rate of their disappearance in these experiments was obscured by the presence of both these phospholipids in the rumen micro-organisms, phosphatidylcholine being exclusively in the protozoa and phosphatidylethanolamine largely in the bacteria.

\section{Rumen metabolism of galactolipids}

In Fig. I is shown the rapid disappearance of galactolipids from the rumen when ${ }^{14} \mathrm{C}$-labelled grass was administered together with $1000 \mathrm{~g}$ of non-radioactive grass. Within $4 \mathrm{~h}, 95 \%$ of the ${ }^{14} \mathrm{C}$-labelled monogalactosyldiglyceride and $78 \%$ of the digalactosyldiglyceride had been degraded. In comparison, the loss of $\beta-\left[{ }^{14} \mathrm{C}\right]$ carotene during this period or during $23.5 \mathrm{~h}$ was negligible, and that which did occur could be accounted for by passage of digesta to the abomasum. 


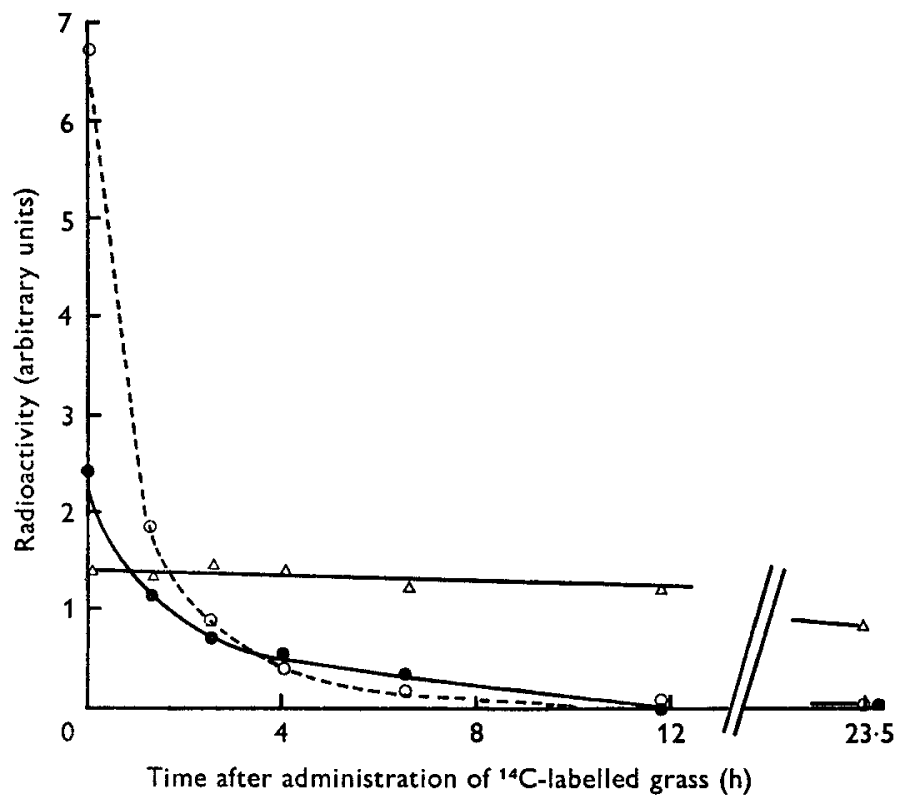

Fig. I. Decomposition of grass galactolipids and carotene in the sheep rumen. ${ }^{14} \mathrm{C}$-labelled grass $(3 \circ \mathrm{g}$, approx. $7.5 \mathrm{mCi})$ was chopped into small pieces and administered at zero time: the sheep was then allowed to eat $900 \mathrm{~g}$ of cut grass over the next $75 \mathrm{~min}$. Lipids were extracted from $50 \mathrm{ml}$ of rumen contents removed at various intervals, separated by column chromatography and the radioactivity determined by scanning the final thin-layer chromatrography plates. The radioactivity is expressed in arbitrary units which are a measure of the area under the peak. (O) Monogalactosyldiglycerides, $(\boldsymbol{\theta})$ digalactosyldiglycerides, $(\triangle)$ carotene (largely $\beta$ ).

When isolated grass $\left[{ }^{14} \mathrm{C}\right]$ galactolipids were incubated with rumen contents there was a rapid hydrolysis of both di- and monogalactosyldiglyceride, with the production of water-soluble radioactivity. The galactolipase activity was completely lost by keeping the rumen contents for $7 \mathrm{~min}$ at $100^{\circ}$. When the rumen fluid was centrifuged ( $100000 \mathrm{~g}$ for $50 \mathrm{~min}$ ) to prepare a supernatant solution free of micro-organisms, most of the activity towards both substrates was present in the pellet; $20-30 \%$ remained soluble.

Examination of the lipids formed by the hydrolysis of both substrates by complete rumen contents indicated that, at all times, free fatty acids were the only detectable products; there was no significant accumulation of monoglycerides, diglycerides or galactosylmonoglycerides. Examination of the water-soluble ${ }^{14} \mathrm{C}$-labelled products by paper chromatography was difficult due to interference by water-soluble substances in the rumen fluid, although the results obtained suggested that the direct deacylation products, i.e. galactosylglycerol and digalactosylglycerol, were formed. However, it was found that the centrifugation pellet from rumen fluid containing the bulk of the galactolipase activity would still actively decompose the substrates if the pellet was resuspended in water rather than in the artificial rumen saline usually used. Here it could be clearly shown that the products, galactosylglycerol and digalactosylglycerol, were formed from monogalactosyldiglycerides and digalactosyldiglycerides respectively. There was evidence of a further breakdown of digalactosylglycerol into galactosylglycerol and then of the latter into galactose and glycerol. 


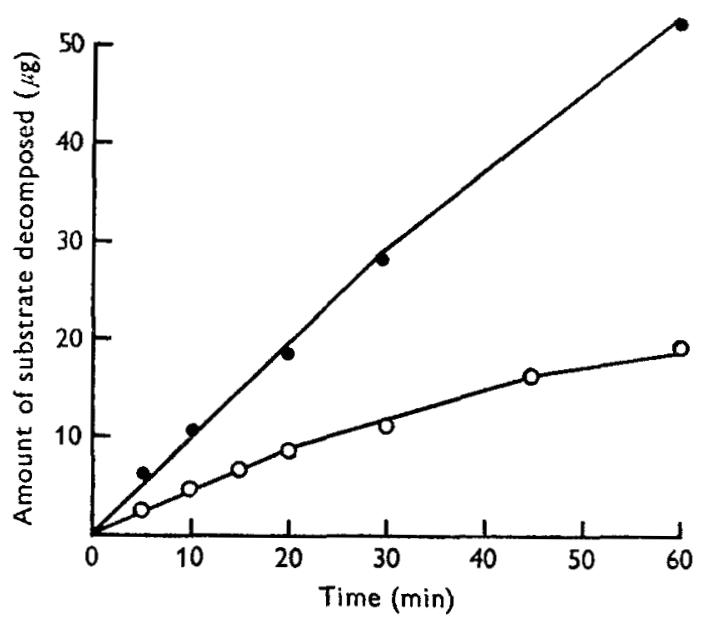

Fig. 2. Time course of decomposition of $0.5 \mathrm{mg}$ pure $\left[{ }^{14} \mathrm{C}\right]$ galactolipid substrates incubated with $\mathrm{I} \mathrm{ml}$ of sheep rumen fluid. (C) Digalactosyldiglycerides, $(O)$ monogalactosyldiglycerides.

'The extent of decomposition of galactolipids showed some variability from day to day even with rumen samples from the same sheep. Sheep undergoing winter feeding on hay and oats, or given grass-nuts diets (which are virtually devoid of galactolipids) still had considerable ruminal galactolipase activity, but this tended to rise by $75^{-}$ $100 \%$ when the animals were put out to spring pasture.

Using the pure substrates prepared from grass, digalactosyldiglycerides were usually deacylated at a somewhat faster rate than monogalactosyldiglycerides (Fig. 2), the reverse of the rates seen during rumen grass digestion (Fig. I). In grass the galactolipids are found in a membrane complex, the digestion of which is likely to be different from that of the isolated substrates. Thus pure digalactosyldiglycerides could be more water-dispersable and accessible to the enzyme than monogalactosyldiglycerides because of the greater bulk of the hydrophilic part of its molecule. With both substrates at a concentration of $0.25 \mathrm{mg} / \mathrm{ml}$, the rate of deacylation was nearly linear for the first $30 \mathrm{~min}$, while during the next $30 \mathrm{~min}$ of incubation there was a slight reduction in the rate of substrate decomposition (Fig. 2). With both galactolipids the extent of breakdown continued to increase as the concentration of substrate added was increased up to $0.5 \mathrm{mg} / \mathrm{ml}$ rumen contents (Fig. 3). This maximum level of decomposition obtained with pure substrates would be equivalent to the contents of a whole rumen (assumed $5 \mathrm{l}$ ) degrading $0.9 \mathrm{~g}$ monogalactosyldiglycerides and $\mathrm{I} \cdot \mathrm{I} g$ digalactosyldiglycerides per $h$.

\section{Decomposition of grass pigments in the rumen}

Examination of chlorophyll $a$ and $b$ pigments suggested that, after ingestion of grass, they were rapidly converted into the corresponding phaeophytins (Fig. 4) which were recognized on paper chromatograms by their colour, phaeophytin $a$ being grey and phaeophytin $b$, a muddy yellow. This was confirmed by elution of these compounds from the paper and determination of their spectra. In the rumen of animals 


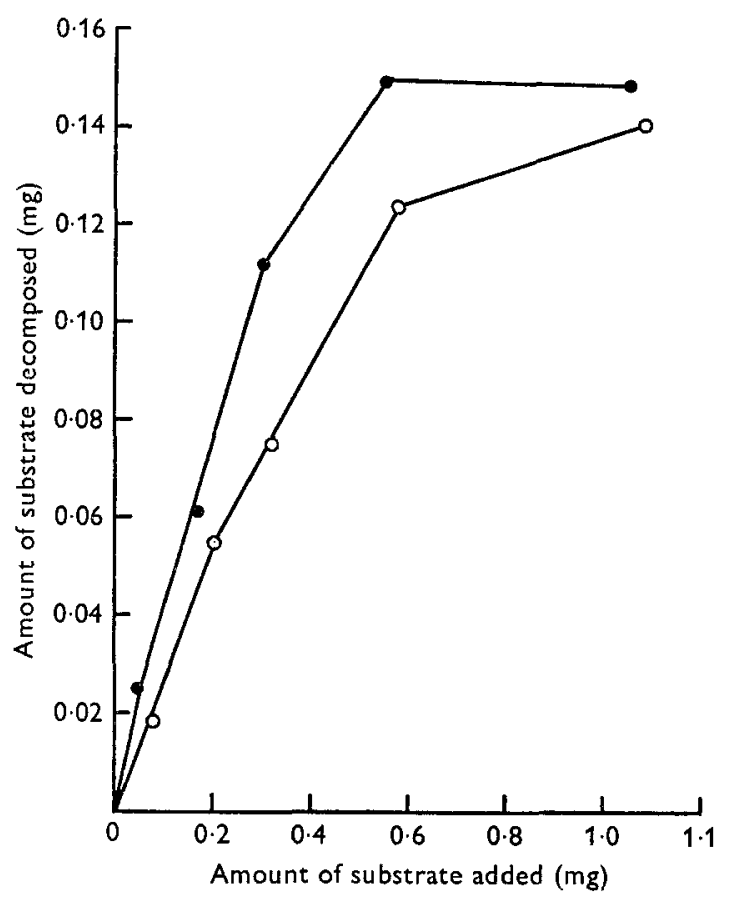

Fig. 3. Decomposition of various amounts of pure $\left[{ }^{14} \mathrm{C}\right]$ galactolipid substrates incubated for $40 \mathrm{~min}$ with $\mathrm{I} \mathrm{ml}$ of sheep rumen fluid. (๑) Digalactosyldiglycerides, (O) monogalactosyldiglycerides.

after $24 \mathrm{~h}$ without food, the concentration of pigments had declined somewhat (Figs. 4, 5) possibly due to passage of digesta from the rumen, though the original chlorophyll pigments were still clearly present. It could be seen from the chromatograms that more chlorophyll $a$ had been converted into phaeophytin $a$ by the loss of $\mathrm{Mg}$ than chlorophyll $b$ into phaeophytin $b$. This was confirmed by analysis of the spectra (Smith \& Benitez, r955) which showed that, after $24 \mathrm{~h}$ without food, the chlorophyll $a$ :phaeophytin $a$ ratio was $\circ \cdot 10$, while the chlorophyll $b$ :phaeophytin $b$ ratio was 0.28 . The phase test suggested that no significant part of the chlorophylls or phaeophytins present in the rumen at various intervals after the end of feeding existed as chlorophyllides or phaeophorbides due to loss of the phytol residue. Some chlorophyll pigments were still detectable in faeces obtained from sheep fed on pasture grass, although the amount related to the corresponding phaeophytin in the faeces was minimal compared with that of rumen contents (Fig. 6). In hay during drying and storage there had been extensive breakdown of chlorophyll pigments of the grass to yield phaeophytins, although again this was more extensive with chlorophyll $a$ than $b$ (Fig. 6). It is apparent that, during grass feeding, a very polar olive-green pigment which remains at the origin during paper chromatography also accumulates in the rumen. This material could be separated from grass pigments and phaeophytins by thin-layer chromatography (Fig. 5); its chromatographic properties were similar to those of phylloerythrin and, when eluted, its spectrum was the same as this porphyrin. These 


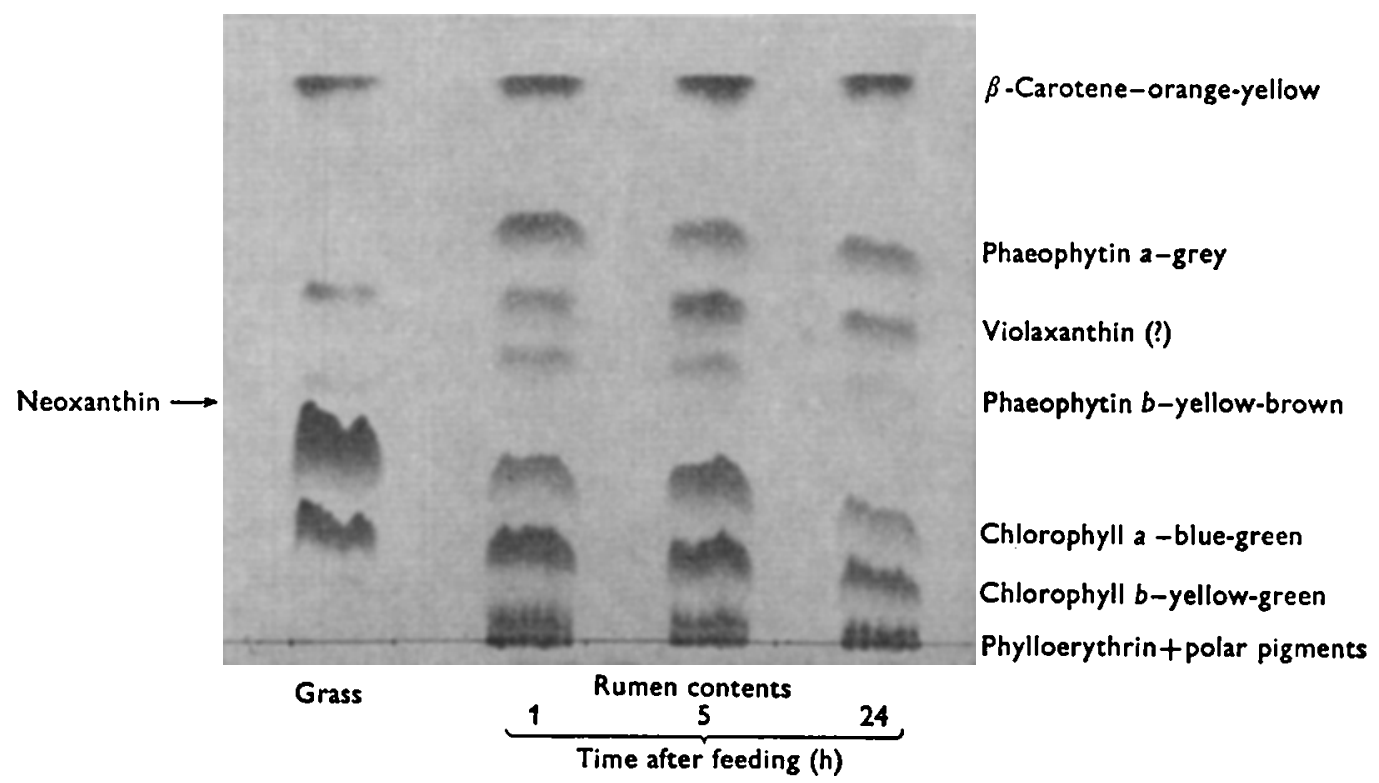

Fig. 4. Paper chromatogram of pigments in grass and sheep rumen contents $\mathrm{I}, 5$ and $24 \mathrm{~h}$ after the end of grass feeding.

experiments (and subsequent ones using ${ }^{14} \mathrm{C}$-labelled grass) suggested that there was an initial conversion of about half the chlorophyll pigments into phylloerythrin within the first few hours after the ingestion of grass and that the level of phylloerythrin then remained constant, apart from loss in the digesta passing to the abomasum. During starvation, there also appeared in the rumen other pigments which were not normally present, although the amount and time was variable from animal to animal (Fig. 5). Pigment 7 was yellowish-green and had a major peak at $454 \mathrm{~nm}$ and a minor one at $632 \mathrm{~nm}$. Pigment 9 was brown, with large peaks at $412 \mathrm{~nm}$ and $668 \mathrm{~nm}$.

\section{Source of enzymes responsible for lipid breakdown}

When grass was homogenized in 'rumen saline' and incubated for $\mathrm{I} h$ at $38^{\circ}$ under $\mathrm{N}_{2}$, extraction and examination of the lipids showed that substantial changes had occurred. There had been an appreciable breakdown of galactolipids and both phosphatidylethanolamine and phosphatidylcholine, and phosphatidic acid and free fatty acids had accumulated. Chlorophyll $a$ had substantially broken down to phaeophytin $a$, while some decomposition of chlorophyll $b$ had also occurred, although this was much less marked. Grass homogenates, and to a lesser extent those of hay, also catabolized both ${ }^{14} \mathrm{C}$-labelled grass galactolipid and lecithin.

It is apparent that the grass eaten and the rumen micro-organism population must each be considered as sources of the enzymes which bring about lipid breakdown. The cellular structure of grass is disrupted during mastication, so much so that in the cow bolus most of the chloroplasts are ruptured (J. L. Mangan, personal communication). Such cellular damage could promote rapid enzymatic decomposition of the lipids. It was not possible to collect boluses from sheep which were eating grass, but 


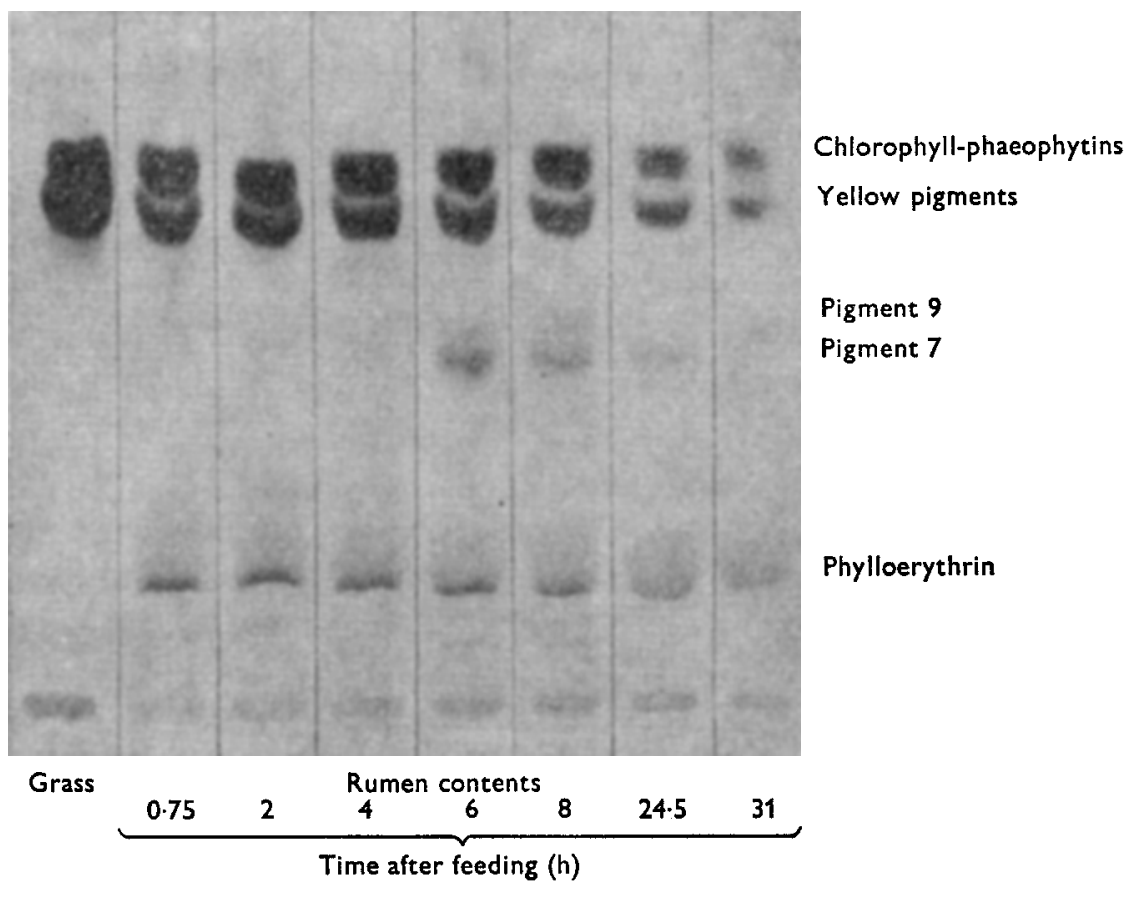

Fig. 5. Thin-layer chromatogram of the polar pigments of grass and in sheep rumen contents at various intervals after the end of grass feeding. At each time the pigments present represent those in $0.15 \mathrm{ml}$ of rumen contents.

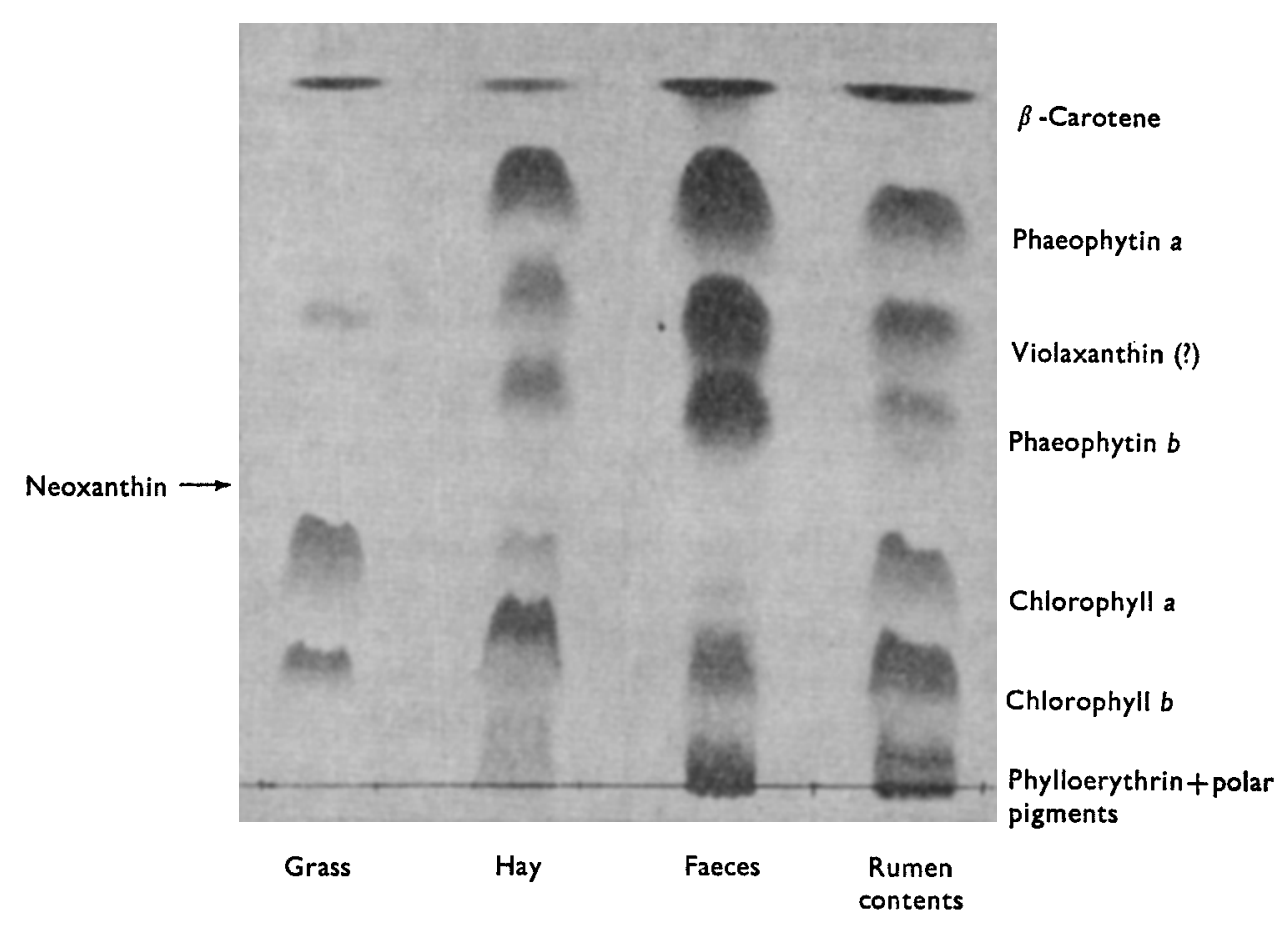

Fig. 6. Paper chromatogram of pigments in grass, hay, faeces and rumen contents of a sheep feeding on grass pasture. The faeces pigments have been over-loaded to show the residual chlorophyll pigments. 
boluses were obtained manually through a large fistula in the rumen of a cow, being collected as they were delivered through the cardia (Reid, Lyttleton \& Mangan, 1962). Such boluses, when extracted with chloroform-methanol within 5 min of collection, contained almost the same lipids as the grass being eaten, and thus little enzymatic decomposition had occurred. However, whereas the control grass lipid contained phosphatidylethanol, this was completely absent from the bolus. Since it has been shown that this phospholipid is an artefact formed by the action of phospholipase $\mathrm{D}$ in the grass transferring a 'phosphatidyl' moiety to the ethanol in the solvent (Table I), the chewing of the grass and its admixture with saliva had prevented this transfer. In a subsequent paper the isolation of an active inhibitor of phospholipase $\mathbf{D}$ from bovine saliva will be described.

Rumen contents removed from a pasture-fed sheep after fasting $18 \mathrm{~h}$ had a high capacity to decompose both grass galactolipids and lecithin, although the decomposition of chlorophyll pigments added as a grass homogenate was minimal. The rate of hydrolysis of galactolipids and phospholipids seemed to be many times that calculated from the grass content of the rumen computed from the spectral analysis of chlorophyll and phaeophytin pigments, and assuming that the grass enzymes themselves were not broken down. Since it is likely that the enzymes would be extensively decomposed in the rumen during the period of starvation, the results suggest that most, if not all, the hydrolysis of the herbage lipids (galactolipids and phospholipids) is brought about by enzymes of rumen micro-organisms.

\section{DISCUSSION}

\section{Metabolism of grass glycolipids in the rumen}

All the experiments confirm that the the rumen contains active enzymes for hydrolysing the galactolipids of plant chloroplasts. The activities demonstrated during experiments in vitro would be quite adequate for decomposing the calculated intake of digalactosyldiglycerides and monogalactosyldiglycerides of a sheep eating pasture: Under the present conditions it would appear that the main breakdown pathway is via a direct lysis of the two esterified fatty acids (presumably through short-lived galactomonoglyceride intermediates) yielding the galactosylglycerol residue of the molecules. In this context Bailey (1962) found that, although cell-free extracts of bovine rumen bacteria hydrolysed mono- and digalactosylglycerol, they did not liberate galactose from intact galactolipids, indicating that prior lipolysis was necessary. On the other hand, Bailey \& Howard ( 1963 ) showed that soluble extracts of the rumen protozoa Epidinium ecaudatum contained a galactosidase which liberated galactose from plant galactolipids without producing free fatty acids. Mammalian brain is also known to contain a galactosidase which can release galactose fom plant digalactosyldiglycerides (Subba Rao \& Pieringer, 1970). Although no evidence could be found for this pathway in the present investigation, it could exist as a minor decomposition pathway in rumen protozoa, which are known to ingest actively any chloroplasts remaining intact after mastication of the food (Mangan \& Pryor, 1968).

The enzymes involved in the subsequent decomposition of mono- and digalactosyl- 
glycerol are presumably the $\alpha$ - and $\beta$-galactosidases shown by Conchie \& Levvy (1957) and Bailey (1962) to be present in sheep rumen micro-organisms.

The main routes of degradation are therefore likely to be:

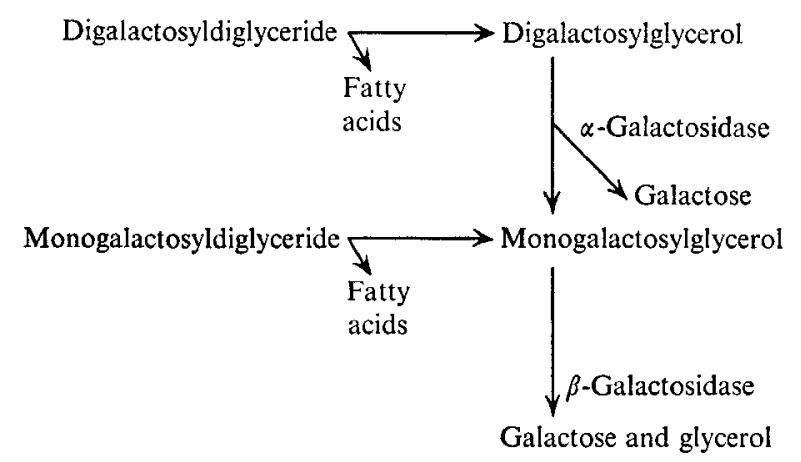

It would seem from the present investigation that grass contains enzymes that can break down its own galactolipids. A deacylating enzyme acting on both mono- and digalactosyldiglycerides is present in some, but by no means all, leaves (Sastry \& Kates, 1964; Helmsing, 1969). Presumably this enzyme is also present in grass. However, the present results do not indicate that this is the only source of the enzyme which acts on dietary grass glycolipids in the rumen. Thus, the very active galactolipase existing after $24 \mathrm{~h}$ starvation probably comes mainly from micro-organisms, since most dietary proteins would have been broken down at this stage (Mangan, 1972).

\section{Decomposition of grass pigments in the rumen}

It is apparent that, in the grass-fed sheep, there is a rapid release in the rumen of $\mathrm{Mg}$ from both chlorophyll pigments ingested, resulting in the formation of phaeophytins. The precise cause of this change is not clear; in a cow it is not brought about as a result of cellular damage during the primary mastication. However, when grass homogenates themselves are incubated for a period with a saline solution phaeophytins are produced, possibly through the development of acidic conditions which can promote loss of $\mathrm{Mg}$. No clear evidence was obtained that micro-organisms are involved in the preliminary detachment of $\mathrm{Mg}$ and if they are it is puzzling that some of the chlorophyll pigment remains intact after a long period of starvation. Chlorophyll $a$ loses its $\mathrm{Mg}$ more readily than chlorophyll $b$ in the rumen: a similar differential breakdown has previously been observed with the decomposition of chlorophylls in plant tissues and by soil micro-organisms (Hoyt, 1964). The $\mathrm{Mg}$ loss does not depend on the growth of certain types of rumen micro-organism or the development of adaptive enzymes in the presence of chlorophyll, because two sheep fed on pasture grass after over-wintering on a virtually chlorophyll-free diet were immediately able to bring about the same degradation of chlorophyll. Clearly, therefore, the phenomenon is unlikely to be associated with the hypermagnesaemia of sheep and cattle during the initial period of pasture grazing in the spring (Rook, 1969).

The phase test showed that very little of the residual chlorophyll or phaeophytin in 
the rumen had lost phytyl side-chains through the action of the enzyme chlorophyllase, so it would appear that the $\mathrm{Mg}$ loss is the only change that an appreciable part of the chlorophyll pigments undergo. On the other hand, it is clear that about half the chlorophyll pigments undergo further decomposition to the pigment phylloerythin. Possibly this could represent metabolism of any intact chloroplasts ingested by the rumen protozoa (Mangan \& Pryor, 1968; West \& Mangan, 1972). Phylloerythrin has long been recognized as a chlorophyll decomposition product in the alimentary tract of ruminants (Inman \& Rothemund, I93 I; Fisher \& Stadler, 1936). Under conditions in which ingestion of chlorophyll is excessive, or decomposition of the pigment in the liver is impaired, it can accumulate in the blood and produce photosensitization of the animal (Rimington \& Quin, 1933; Quin, Rimington \& Roets, 1935). Liberation of phytol caused through phylloerythin formation is likely to lead to the production of phytanic acid, a well-known minor constituent of ruminant tissues (Lough, 1964; Hansen, 1965). The double bond in phytol can be hydrogenated in the rumen to yield dihydrophytol (Patton \& Benson, 1966) which can then be oxidized to phytanic acid by rumen micro-organisms (Hansen, $\mathrm{I} 966$ ). The present work shows that, under conditions of starvation, other decomposition products of chlorophyll are formed in the rumen, but these have never been detected in sheep under continuous-grazing conditions, so with an adequate food supply it is likely that other dietary substrates are preferred by the rumen micro-organisms.

The present studies gave no evidence of metabolism of the $\beta$-carotene contained in grass during passage through the intact rumen. This confirms earlier studies which have suggested that carotenes are resistant to prolonged incubation with rumen contents (Shorland, Weenink, Johns \& McDonald, I957; Wright, 1959).

The help of Mr D. W. Grime in preparing ${ }^{14} \mathrm{C}$-labelled grass and of Dr P. Kemp in fistulating sheep is acknowledged.

\section{REFERENCES}

Allen, C. F., Good, P., Davis, H. F., Chisum, P. \& Fowler, S. D. (1966). F. Am. Oil Chem. Soc. 43, 223.

Bailey, R.W. (1962). Nature, Lond. 195, 79.

Bailey, R. W. \& Howard, B. H. (1963). Biochem. F. 87, I46.

Bray, G. A. (1 960). Analyt. Biochem. 1, 279.

Conchie, J. \& Levvy, G. A. (1957). Biochem. F. 65, 389 .

Cook, L. J., Scott, T. W., Faichney, G. J. \& Lloyd-Davies, H. (I972). Lipids 7, 83.

Czerkawski, J. W. (1967). Br. F. Nutr. 21, 599.

Dawson, R. M. C. (1959). Nature, Lond. 183, 1822.

Dawson, R. M. C. (1967a). In Lipid Chromatographic Analysis p. 163 [G. V. Marinetti, editor]. New York: M. Dekker Inc.

Dawson, R. M. C. (1967b). Biochem. F. 102, 205.

Fisher, H. \& Stadler, F. (1936). Hoppe-Seyler's Z. physiol. Chem. 239, I67.

Garton, G. A. (1960). Nature, Lond. 187, 511 .

Garton, G. A. (1964). In Metabolism and Physiological Significance of Lipids p. 335 [R. M. C. Dawson. and D. N. Rhodes, editors]. London: John Wiley and Sons.

Garton, G. A., Hobson, P. N. \& Lough, A. K. (1958). Nature, Lond. 182, I5I I.

Garton, G. A., Lough, A. K. \& Vioque, E. (I96I). F. gen. Microbiol. 25, 2 I 5.

Grossbard, E. \& Barton, G. E. (1963). Int. Y. appl. Radiat. Isotopes 14, 5 I 7.

Hansen, R. P. (1965). N.Z. $\mathscr{f l}$ Sci, 8, 158.

Hansen, R. P. (1966). F. Dairy Res. 33, 333. 
Hawke, J. C. \& Silcock, W. R. (I969). Biochem. F. I12, I3I.

Helmsing, P. J. (1 969). Biochim. biophys. Acta 178, 5 r9.

Hoyt, P. B. (1964). The decomposition of plant chlorophyll and its derivatives in soil. Ph.D. Thesis, University of London.

Inman, O. L. \& Rothemund, P. (1931). Science, N.Y. 74, 221.

Jeffrey, S. W. (1961). Biochem. F. 80, 336 .

Kates, M. (1 970). Adv. Lipid Res. 8, 225.

Kepler, C. R., Tucker, W. P. \& Tove, S. B. (197I). F. biol. Chem. 246, 2765.

Lough, A. K. (1964). Biochem. $7.91,584$.

Mangan, J. L. (1 972). Br. F. Nutr. 27, 26I.

Mangan, J. L. \& Pryor, M. J. (1968). F. Physiol., Lond. 200, I8P.

Patton, S. \& Benson, A. A. (1966). Biochim. biophys. Acta 125, 22.

Quin, J. I., Rimington, C. \& Roets, G. C. S. (1935). Onderstepoart $\mathscr{7}$. Vet. Sci. 4, 463.

Reid, C. S. W., Lyttleton, J. W. \& Mangan, J. L. (r962). N.Z. Fl agric. Res. 5, 237.

Rimington, C. \& Quin, J. I. (1933). Nature, Lond. 132, 178.

Rook, J. A. F. ( 1969). Ann. N.Y.Acad. Sci. 162, 727.

Roughan, P. G. \& Batt, R. D. (1969). Phytochemistry 8, 363.

Sastry, P. S. \& Kates, M. (1964). Biochemistry, Easton 3, 1280.

Shorland, F. B., Weenink, R. O., Johns, A. T. \& McDonald, I. R. C. (1957). Biochem. F. 67, 328.

Smith, J. H. C. \& Benitez, A. (I 955). In Modern Methods of Plant Analysis Vol. 4, p. I 42 [K. Paech and L. Tracey, editors]. New York: Springer-Verlag.

Subba Rao, K. \& Pieringer, R. A. (1970). F. Neurochem. I7, 483.

Trevelyan, W. E., Procter, D. P. \& Harrison, J. S. (1950). Nature, Lond. r66, 444.

Vorbeck, M. L. \& Marinetti, G. V. (1965). J. Lipid Res. 6, 3 .

Warner, A. C. (1956). F. gen. Microbiol. 14, 733.

West, J. \& Mangan, J. L. (1972). Proc. Nutr. Soc. 31, I08A.

Wright, D. E. (1959). Nature, Lond. $184,875$. 